\title{
Can agents sensitive to cultural, organizational and environmental issues avoid herding?
}

\author{
Blasco, $\mathrm{N}^{\text {a }}$. \\ Corredor, $\mathrm{P}^{\mathrm{b}, \mathrm{c}}$. \\ Ferreruela, Sa.
}

a Department of Accounting and Finance. Faculty of Economics. Gran Vía 2, 50005 Zaragoza, Spain. e-mail: nblasco@unizar.es and sandrafg@unizar.es

${ }^{b}$ Department of Business Administration. Faculty of Economics Campus de Arrosadía s/n, 31006 and

cInstitute for Advanced Research in Business and Economics (Inarbe), Pamplona, Spain. e-mail: corredorp@unavarra.es

This paper has received financial support from the Spanish Ministry of Economy and Competitiveness (ECO2016-77631-R and ECO2013-45568-R), and the Government of Aragón/European Social Fund (S14/2).

(C) 2017. This manuscript version is made available under the CC-BY-NC-ND 4.0 license http://creativecommons.org/licenses/by-nc-nd/4.0/ 


\begin{abstract}
Our findings indicate that herding behavior is affected not only by the cultural variables already discussed in the literature but also by other variables associated with organizational and environmental issues such as governance, technology, education and training, business style and conditions, and the development of equity and non-equity markets. Some of these act as catalysts, for example governance and technology. Others may have a corrective effect, such as the development of financial markets, business style, and education and training. If corrective factors are sufficiently developed, intentional herding practices could be reduced in the future.
\end{abstract}

KeyWords: herding, culture, governance, education and training, financial development, business style, technology.

\title{
1-Introduction
}

Since ancient times, imitation has been a resource used to learn and to make decisions. Herding appears in a market when investors opt to imitate the trading practices of those they consider to be better informed, rather than acting upon their own beliefs and private information (see Lo [1999] or Loewenstein [2000], among others).

But financial decisions are not necessarily structured decisions. There are no complete models involving all the variables affecting the decision and the relationships among them (Barberis and Thaler (2003), Shiller and Pound (1989), Shiller (1999), Kuran and Sunstein (1999), Stasser and Titus (1985) or Stasser et al. (1989)).

According to Fremount et al. (1970) and Hogarth (2001), decision making is a conscious and human process involving both individual and social phenomena. Whenever agents are involved in making decisions, a number of factors can affect the process they follow and ultimately the decision they make. The factors can be organized into three major groups: perception issues (influenced by the background and experience of the perceiver), organizational issues (policies and procedures, hierarchy, legislation, politics) and environmental issues (economic, financial or technological development).

Previous studies in the literature discuss the relevance of the six dimensions of cultural paradigms proposed by Professor Geert Hofstede in order to explain both social and individual behavioral patterns. But culture changes very slowly and cultural dimensions are only calculated over long periods of time. In order to detect the influence on herding of other more dynamic factors, we take into account, in addition to the cultural factors suggested in Chang and Lin (2015), other issues that have to do with the degree of governance of a country, with its educational and professional training system, with the environment in which its companies do business, with its technology development and with some specific financial factors reflecting the state of its financial development.

This paper attempts to shed light on general issues (both organizational and environmental) influencing the trend towards herding practices in 35 different 
countries. As personal issues are much more difficult to model, comprise very different aspects and are less generalizable (they can, at most, be generalized through what we call cultural issues), the main contribution of this paper is based on the incorporation of a wide range of organizational and environmental variables that may affect herding behavior. We try to analyze whether specific country characteristics determine herding intensity.

The usefulness of this article is twofold. On the one hand, it is interesting to know which organizational or environmental issues are able to mitigate or correct herding behavior and which factors can enhance or catalyze herding practices. On the other hand, our results may shed light on the extent to which herding behavior may be avoidable if it is not considered appropriate.

\section{2- Database}

The empirical study focuses on a sample of listed stocks of 35 international markets for a 15-year period from January 2000 to June 2015. Market selection is based on trying to cover those markets previously analyzed in the literature, together with some other stock markets that seem to have been underestimated despite their importance in financial terms. The final sample consists of 141,365 market-day observations and arises from the stock returns of 39,096 companies from all the countries under study.

This study has been carried out using daily returns on all common stocks and the daily returns on the market indexes obtained from Datastream (Thomson Financial). The database has been checked and corrected according to the recommendations of Ince and Porter (2006). In addition to the stock returns and the cultural variables associated to perception issues, we use a broad set of variables representing the organizational and environmental issues under study. The data are obtained from multiple sources. These variables can be grouped as follows, according to their communality:

\section{Cultural dimension}

The Hofstede index $(2001,2010)$ is a six-dimensional model of national cultures. The six dimensions comprise the following: power distance index (pdi), individualism versus collectivism (idv), masculinity versus femininity (mas), uncertainty avoidance index (uai), long-term orientation versus short-term normative orientation (lto) and indulgence versus restraint (ivr) ${ }^{1}$. The effect of these variables on the herding level in the markets is not expected to be homogeneous. Since Hofstede introduces six representative variables of the cultural dimension, the same number of variables has also been used in the other dimensions (see below) for the sake of homogeneity.

\section{Governance dimension}

This group comprises information on how countries exercise authority at an institutional level. Greater governance will produce greater confidence in market investors, which promotes a greater attraction of all types of investors. This may result in investors having more information and confidence in their actions, so

\footnotetext{
${ }^{1}$ Source web page of Hoftsede.
} 
herding may decline. However, attracting more investors can result in the appearance of uninformed investors, who might induce greater herding. Therefore, the observed result on herding is an empirical question. The variables included in this group are taken from the Worldwide Governance Indicators gathered by the World Bank, and are as follows: Voice and accountability (va), political stability and absence of violence (ps), government effectiveness (ge), regulatory quality (rq), rule of law (rl) and control of corruption (cc). In all cases, the higher the value of the variable, the more governance is enhanced.

\section{Technology dimension}

The technological development of a country certainly affects the behavior and habits of its inhabitants. A higher technological capacity is associated with more training and greater intellectual development. Improved technology produces an increase in the dissemination of information and of negotiation, which will induce less herding. However, further technological development can democratize access to investing, which may cause less informed investors to start trading. The result of the effect of these variables on herding is thus an empirical question. The variables considered are: Innovation (inn), company spending on R\&D (srd), individuals using internet \% (iui), firm-level technology absorption (tab), technological readiness (trd), FDI and technology transfer (fdi) ${ }^{2}$.

\section{Education and training dimension}

This section comprises variables relating to the quality of education and intellectual capacity of the inhabitants of the country. A higher score should lead to a lower level of herding, since investors will have a greater capacity for decisionmaking and will be less influenced by the actions of other investors. The variables included are: Higher education and training (het), availability of research and training services (arts), on-the-job training (ojt), extent of staff training (est), intellectual property protection (ipp) and quality of scientific research institutions (qsri).

\section{Business style and conditions dimension}

The business style of a company directly affects how investors trade in its stocks. Insider trading, bad practices or fraud have all led to the collapse of well-known companies and had a negative impact on the markets in the recent past. The more ethical the behavior of companies, the more transparency they show and the better the information they report, then the higher the level of confidence in them will be. The effect this may have on herding is evident, since better information about a company and greater confidence will generate less uncertainty and, therefore, less need for investors to track other investors. The variables used are as follows: willingness to delegate authority (wda), business impact of rules on FDI (bir), reliance on professional management (rpm), efficacy of corporate boards (ecb),

\footnotetext{
2 The reference source for information on technology, education and training, and business style and conditions is the World Economic Forum.
} 
strength of auditing and reporting standards (sars) and ethical behavior of firms (ethb).

\section{Financial development dimensions}

The development of the financial market, like governance, can have a diverse effect on herding. On the one hand, further development implies more information, security and investor confidence, which a priori would indicate less herding. However, as in the case of other dimensions, these elements can attract less informed investors who need to act in accordance with other participants. Therefore, the final result depends on which part has more weight and thus prevails over the other.

The area of Financial development is analyzed from two different dimensions: equity markets and non-equity markets. The development of equity markets includes the following variables: Protection of minority shareholders' interests (pmsi), financing through local equity market (flem), efficiency (eff), venture capital availability (vca), trustworthiness and confidence (tac) and number of listed companies per 1,000,000 people (nlc). The development of non-equity markets includes: outstanding international private debt securities to GDP (oipds), international debt issues to GDP (idi), life insurance premium volume to GDP (lipv), nonlife insurance premium volume to GDP (nlipv), pension fund assets to GDP (pfa) and private credit by deposit money banks to GDP (pcdmb) ${ }^{3}$.

\section{3- Research Design and Results}

The methodology and results are described in three phases:

\section{1-Phase 1: Herding in the stock markets}

We use the methodology proposed by Chang et al. (2000) and Chiang and Zheng (2010) in order to test the presence of herding in a wide range of stock markets.

Table 1 presents these results. It can be seen that 30 out of the 35 markets analyzed exhibit significant herding behavior. Regarding the global estimates, we find evidence of significant herding. Our results are in line with those presented in Chen (2013) and Chang and Lin (2015), with some minor differences that may be attributed to different time periods and to a different estimation process.

\section{2-Phase 2: Herding and modulating variables.}

Once the presence of herding has been generally detected in stock markets, it is interesting at this stage to test whether some other variables may affect herding behavior either reducing or increasing its intensity.

The analysis consists of estimating the 42 pool regressions of all countries. In order to standardize the information and make it comparable, modulating variables are transformed into dummy variables. Thus, if a particular observation of a variable is above the median of that variable (calculated using all periods and all countries), it takes the value 1 , and 0 otherwise. The following equation is estimated accordingly:

\footnotetext{
3 The variables to measure this aspect are taken from World Bank information except protection of minority shareholders' interests, financing through local equity market, efficiency, venture capital availability, trustworthiness and confidence, all of which are taken from the World Economic Forum.
} 
$C S A D_{i, t}=\alpha+\gamma_{1} C S A D_{i, t-1}+\gamma_{2} R m_{i, t}+\gamma_{3}\left|R m_{i, t}\right|+\gamma_{4}\left[R m_{i, t}\right]^{2}+\gamma_{5} D V_{i, t}^{s}\left[R m_{i, t}\right]^{2}+\gamma_{6} \log G D P_{i, t}+\varepsilon_{i, t}$

where $\mathrm{CSAD}_{\mathrm{i}, \mathrm{t}}$ is the cross-sectional absolute deviation in stock market $\mathrm{i}$ on day $t, R m_{i, t}$ is the index return in the same market on the same day and $\mathrm{DV}$ s is the dummy variable for one individual component of a dimension (a total of 42 individual variables). As some of these variables may be closely associated with the level of economic development of a country, the natural logarithm of GDP per capita has also been included in the regression analysis as a control variable ${ }^{4}$.

The results are presented in table 2 . They indicate that most of the variables analyzed are significant and, with the exception of some cultural variables, their effect on herding is corrective. Their positive sign suggests that, individually considered, these variables tend to decrease herding practice.

\section{3- Phase 3: Estimation of the combined effect of all dimensions on herding.}

At this stage, the first step is to summarize in a factor or indicator the set of variables that have been considered within each dimension. Such an indicator is calculated for each dimension and for each country under analysis. We use Iterated Principal Factor Analysis for factor extraction, our main objective being to reduce the dimensionality of our set of multivariate data. We perform this analysis for each dimension except for cultural variables, which require individual evaluation given their data structure ${ }^{5}$. The Kaiser-Meyer-Olkin Measure of Sampling Adequacy for our dimensions is, in all cases, above 0.5 , the minimum corresponding to non-equity markets (0.6658) and leaving all others above 0.75 , with the maximum attributed to governance variables (0.9063). Applying the Minimum Average Partial (MAP) test (Velicer, 1976) to the calculated components, only a single factor is needed to significantly explain the variance of the original set of variables in our data base. The analysis has been performed for each dimension using aggregated data, so that the weight of each individual variable in the new indicator remains constant across countries. Once the structure of the factor for one dimension is defined, we calculate the corresponding dimension factors for each country.

It can be considered that mediating factors related to financial development, governance, intellectuality, business style and technology can be linearly dependent (Francis et al (2003), Davis-Friday (2010), Rahman et al. (2010) or Boolaky et al. (2013) are some of the examples of the extant research in this area). In order to avoid misleading results, these variables need to be orthogonalized. As in equation 1, we also include the natural logarithm of GDP per capita. This variable has also been orthogonalized.

Then, we run the following pool regression with fixed effects for each country and year:

\footnotetext{
${ }^{4}$ This variable is significantly negative for all estimates. Nevertheless, we have also carried out the pool estimation without it and the results do not change significantly.

5 The lack of aggregation of cultural variables is due, in addition to the invariant structure of the data, to the difficulty of attributing a reasonable meaning to the final aggregated indicator.
} 


$$
\begin{aligned}
& C S A D_{i, t}=\alpha+\gamma_{1} C S A D_{i, t-1}+\gamma_{2} R_{m, t}+\gamma_{3}\left|R_{m, t}\right|+\gamma_{4}\left[R_{m, t}\right]^{2}+\gamma_{5} C V_{i, t}^{s}\left[R_{m, t}\right]^{2}+\gamma_{6} D F 1_{i, t}\left[R_{m, t}\right]^{2}+ \\
& \gamma_{7} \operatorname{TECH}_{i, t}\left[R_{m, t}\right]^{2}+\gamma_{8} D F 2_{i, t}\left[R_{m, t}\right]^{2}+\gamma_{9} B U S_{i, t}\left[R_{m, t}\right]^{2}+\gamma_{10} E D U_{i, t}\left[R_{m, t}\right]^{2}+\gamma_{11} G O V_{i, t}\left[R_{m, t}\right]^{2}+ \\
& \gamma_{12} \operatorname{LogGDP}_{i, t}+\varepsilon_{i, t}
\end{aligned}
$$

where $\mathrm{CV}^{\mathrm{s}}$ represents each of the six cultural variables under study, so we carry out 6 pool regressions. Each regression includes as independent variables the orthogonalized factors representing the dimensions under analysis together with one dummy cultural variable.

Table 3 shows the pool regression results using the White cross-section covariance option. The logGDP variable is significantly negative. The herding indicator $\gamma_{4}$ is clearly significantly negative, suggesting that the propensity to market consensus is a general finding for the countries under study. With regard to the dummy cultural variables, $i d v$ and mas are significantly negative, indicating that a higher degree of individualism and masculinity increase imitative behavior, whereas uncertainty avoidance produces the opposite reaction. Power distance, long-term orientation and indulgence are not significant at the usual statistical levels. The estimates for the rest of the factors overwhelmingly suggest that both governance and technology induce higher herding levels, while higher levels of financial market development (both equity and non-equity markets), business style, and knowledge and training tend to decrease herding behavior. That is, the effect of herding catalyst dimensions (individualism and masculinity, governance and technology) may be compensated for by herding corrective dimensions (uncertainty avoidance and indulgence, financial market development, business style, and knowledge and training).

\section{4- Discussion}

Comparing the results of the combined effect on herding in table 3 with those referring to individual orthogonalized cultural variables affecting herding in table 2 , we can conclude that the mere inclusion of cultural variables can lead to misleading interpretations given their interactions with other organizational and environmental issues. Individually, all the cultural variables except individualism and indulgence promote herding significantly. However, when the combined effect is considered, the only variable that keeps its significance and sign is masculinity, indicating that higher levels of masculinity increase herding. This result is consistent with that obtained in an analysis of cultural variables by Chang and Lin (2015). Our results also indicate that other cultural variables lose relevance or change from positive/negative estimates to negative/positive estimates when combined with organizational or environmental issues. Although it is difficult to distinguish empirically whether individualism and masculinity are incentives to spurious or intentional herding, there are no clear arguments to rule out intentionality bearing in mind that both concepts are related to looking after oneself and personal achievement, which clearly influence decision making.

Something similar occurs with the variables belonging to the governance and technology dimensions. When combined, their corresponding factors have negative estimates whereas their individual components initially appeared to correct herding 
behavior. These comparisons suggest that it is advisable to analyze the joint influence of all the issues that are thought to affect herding behavior.

Governance holds much sway over the financial markets. First because of regulatory issues, which may sometimes induce uniformity and pooling behavior if regulation does not actively strive to induce behavioral diversity. Second because perceptions of the quality of public services, policy formulation and implementation, and the credibility of the government's commitment to such policies (fiscal and monetary policy, trade agreements or international relations) have a profound effect on the financial marketplace, causing either bullish sentiments or market panic. It is possible that all these aspects significantly contribute to the existence of an unintentional herding that is practised by groups facing similar decision problems and information sets and reacting to commonly known public information. In fact, as Bikhchandani and Sharma (2001) suggest, the most important reasons for intentional herd behavior are imperfect information, concern for reputation, and compensation structures that compare one's performance with that of other similar professionals. Governance variables seem to be less related with these issues that encourage intentional herding.

Turning now to technology as an instigator of herding, it has already been mentioned that this can contribute to the dissemination of information and easing the access of investors to market trading. In fact, one important change in trading procedures during recent years has been the functioning of high frequency trading platforms (HFT) that use powerful computers to transact a large number of orders at very fast speeds. This technological progress influences institutional investors' trading behavior and the ways in which their trading strategies, in turn, affect market quality. Trading by HFT can noticeably improve market liquidity but, according to Sornette and Von Der Becke (2011), liquidity may reach a point beyond which the risk of herding increases. HFT uses short-term information as well as adaptive algorithms and provides liquidity at the expense of other market participants. Short term traders may be specifically prone to herding in reaction to the same information. Their reactions to the same signal are very similar and even can lead to large transient instabilities driving prices further away from their fundamentals. According to Xue et al. (2014), HTF produces noise herding which camouflages informed trading.

As previously mentioned, uncertainty avoidance, equity and non-equity market development, business style, and education and training are useful for correcting herding behavior. Interestingly, when the cultural variable being analyzed is masculinity, the education and training dimension is no longer significant even though this dimension maintains its mitigating effect when combined with the rest of the cultural variables. This suggests the importance of masculinity as an explanatory variable for herding in stock markets, indicating that competition, achievement and success, with success being defined as being the winner in the field, are more significant than professional training. Nevertheless, these attitudes which may be thought to reduce herding behavior are in fact promoters of more intense herding practices.

In the light of these findings, can herding, or at least intentional herding, eventually be avoided? Some perception factors that can increase herding such as 
individualism and masculinity are cultural values and, therefore, hardly modifiable. Their influence on intentional herding practice is almost unavoidable. However, organizational and environmental factors are more easily modifiable. A higher level of governance is desirable because it induces trust and confidence. Nevertheless, this reduction in uncertainty may reduce the interest in information acquisition. In parallel, technological developments and especially information technologies favor relational capital and information acquisition needed for decision-making. These dimensions reduce the cost of information acquisition and therefore, in the absence of further incentives, contribute to herding practices. Although the benefits of both a better level of governance and technological development may suggest that herding cannot be avoided, we must consider that both governance and technology have a marginal catalytic effect on intentional herding which may be offset by the corrective forces originated by other dimensions. In fact, approximately $60 \%$ of the countries under analysis with the highest levels of governance and technology also have the highest levels of financial development, education and training, and business style. At the same time, the $40 \%$ of countries with the lowest levels of governance and technology have, in turn, the lowest levels of other dimensions. These data, while confirming the need for the orthogonalization process, suggest that a sufficient strengthening of corrective factors such as the development of equity and non-equity financial markets, education and training or business style and conditions, all of which clearly depend on political, social and organizational will, could well lead to a reduction in intentional herding practices in the future.

\section{5-Conclusions}

The aim of this paper is to verify empirically whether herding is linked to a group of variables associated with cultural, institutional, financial, economic, educational and technological factors that are likely to affect investors' behavior and decisions.

Our findings indicate that herding behavior, which is found in 30 out of the 35 countries under analysis, is affected not only by the cultural variables previously reported in the literature but also by other variables associated with organizational and environmental issues such as governance, technology, education and training, business style and conditions, and the development of equity and non-equity markets. Some of these act as catalysts to herding, for example individualism and masculinity as cultural variables, governance and technology. Other variables and factors may correct herding behavior, for example uncertainty avoidance, the development of financial markets, business style, and education and training.

If corrective factors which clearly depend on political, social and organizational will are sufficiently strengthened, intentional herding practices could be reduced in the future. These results are important for policy makers concerned with the possibilities of market integration or with unifying restrictions or regulations in stock markets. They should take into account the importance of each country's characteristics and how these can affect investors' decisions. Investors should also consider this information when they trade in different markets in order to achieve internationally diversified portfolios. 
Table 1. International Herding. We run regressions of cross-sectional absolute standard deviations (CSAD) on the past CSAD, market return, absolute market return and squared market return. The table reports the estimated coefficients and Adjusted R-squared. ${ }^{* * *}$, ${ }^{* *}$ and ${ }^{*}$ indicate statistical significance at $1 \%, 5 \%$ and $10 \%$ respectively. Ordinary least square regression with White heteroscedasticity consistent standard errors is used in individual country estimation. Pool equation uses ordinary least squares regression with cross-section fixed effects and year dummies. The estimator is designed to accommodate heteroscedasticity (White cross section standard errors).

Equation 0:

$\operatorname{CSAD}_{i, t}=\gamma_{i, 0}+\gamma_{i, 1} \operatorname{CSAD}_{i, t-1}+\gamma_{i, 2} R m_{i, t}+\gamma_{i, 3}\left|R m_{i, t}\right|+\gamma_{i, 4}\left[R m_{i, t}\right]^{2}+\varepsilon_{i, t}$

\begin{tabular}{|c|c|c|c|c|c|c|}
\hline Country & $\gamma_{i, 0}$ & $\gamma_{i, 1}$ & $\gamma_{\mathrm{i}, 2}$ & $\gamma_{i, 3}$ & $\gamma_{i, 4}$ & Adj-R $R^{2}$ \\
\hline All & $0.007^{* * *}$ & $0.480^{* * *}$ & $-0.009^{* * *}$ & $0.557^{\text {*** }}$ & $-5.068^{* * *}$ & 0.796 \\
\hline Argentina & $0.006^{* * *}$ & $0.282^{* * *}$ & $0.047^{* * *}$ & $0.715^{* * *}$ & $-3.400^{* * *}$ & 0.767 \\
\hline Australia & $0.011^{* * *}$ & $0.495^{\text {***}}$ & $0.022^{*}$ & $0.552^{* * * *}$ & 0.374 & 0.812 \\
\hline Austria & $0.006^{* * *}$ & $0.295^{* * *}$ & $-0.041^{* * *}$ & $0.909^{* * *}$ & $-3.631^{* *}$ & 0.632 \\
\hline Belgium & $0.005^{* * *}$ & $0.404^{* * *}$ & 0.007 & $0.766^{* * *}$ & $-3.914^{* * *}$ & 0.657 \\
\hline Brazil & $0.005^{* * *}$ & $0.445^{* * *}$ & $0.026^{* * *}$ & $0.691^{* * *}$ & $-5.990^{* * *}$ & 0.701 \\
\hline Canada & $0.011^{* * *}$ & $0.456^{* * *}$ & $0.077^{* * *}$ & $0.841^{* * *}$ & $-4.188^{* * *}$ & 0.482 \\
\hline Chile & $0.003^{* * *}$ & $0.223^{* * *}$ & $0.071^{\text {*** }}$ & $0.966^{* * *}$ & 3.222 & 0.798 \\
\hline China & $0.003^{* * *}$ & $0.715^{\text {*** }}$ & $-0.092^{* * * *}$ & $0.136^{* * *}$ & $-1.193^{\star * *}$ & 0.711 \\
\hline Denmark & $0.003^{* * *}$ & $0.643^{* * *}$ & 0.005 & $0.545^{* * *}$ & $-2.918^{* * *}$ & 0.770 \\
\hline Finland & $0.004^{* * *}$ & $0.575^{* * *}$ & 0.009 & $0.483^{* * *}$ & $-4.007^{* * *}$ & 0.688 \\
\hline France & $0.004^{* * *}$ & $0.566^{* * *}$ & $0.026^{\text {*** }}$ & $0.697^{\text {***}}$ & $-3.102^{* * *}$ & 0.806 \\
\hline Germany & $0.008^{* * *}$ & $0.488^{* * *}$ & $0.077^{* * *}$ & $0.590^{* * *}$ & $2.763^{* * *}$ & 0.797 \\
\hline Greece & $0.005^{* * *}$ & $0.648^{* * *}$ & $-0.014^{* *}$ & $0.357^{* * *}$ & $-3.620^{* * *}$ & 0.596 \\
\hline Hong Kong & $0.010^{* * * *}$ & $0.362^{* * *}$ & $0.078^{* * *}$ & $0.583^{* * *}$ & $-1.976^{* * *}$ & 0.615 \\
\hline Indonesia & $0.007^{\text {*** }}$ & $0.415^{\text {*** }}$ & $0.050^{* * *}$ & $0.768^{* * *}$ & $-2.370^{* * *}$ & 0.788 \\
\hline Ireland & $0.007^{* * *}$ & $0.403^{* * *}$ & $0.021^{*}$ & $0.759^{* * *}$ & $-2.683^{* *}$ & 0.552 \\
\hline Italy & $0.003^{* * *}$ & $0.638^{* * *}$ & $0.015^{* * *}$ & $0.345^{* * *}$ & $-2.226^{\text {*** }}$ & 0.802 \\
\hline Japan & $0.003^{* * *}$ & $0.690^{* * *}$ & $-0.019^{* * *}$ & $0.303^{* * *}$ & $-1.548^{*}$ & 0.809 \\
\hline South Korea & $0.004^{* * *}$ & $0.745^{* * *}$ & $-0.077^{* * *}$ & $0.265^{* * *}$ & $-2.374^{* * *}$ & 0.822 \\
\hline Malaysia & $0.007^{* * *}$ & $0.446^{* * *}$ & $0.043^{* * *}$ & $0.479^{* * *}$ & $-2.724^{* * *}$ & 0.795 \\
\hline Mexico & $0.004^{* * *}$ & $0.314^{* * *}$ & $0.032^{* * *}$ & $0.718^{* * *}$ & $4.476^{* * *}$ & 0.770 \\
\hline Netherlands & $0.004^{* * *}$ & $0.555^{\text {*** }}$ & $0.018^{* *}$ & $0.461^{* * *}$ & $-2.993^{* * *}$ & 0.684 \\
\hline New Zealand & $0.006^{* * *}$ & $0.346^{* * *}$ & 0.005 & $0.720^{* * *}$ & $-3.271^{* * *}$ & 0.524 \\
\hline Norway & $0.006^{* * *}$ & $0.545^{\text {*** }}$ & $0.025^{* * *}$ & $0.500^{* * *}$ & -0.487 & 0.736 \\
\hline Philippines & $0.007^{* * *}$ & $0.366^{* * *}$ & $0.062^{* * *}$ & $0.800^{* * *}$ & $-1.646^{*}$ & 0.747 \\
\hline Portugal & $0.006^{* * *}$ & $0.301^{* * *}$ & $0.021^{* *}$ & $0.906^{* * *}$ & $-8.345^{* * *}$ & 0.581 \\
\hline Singapore & $0.006^{* * *}$ & $0.484^{* * *}$ & $0.037^{\text {*** }}$ & $0.628^{* * *}$ & $-4.301^{* * *}$ & 0.832 \\
\hline South Africa & $0.007^{* * *}$ & $0.447^{* * *}$ & -0.013 & $0.769^{* * *}$ & $-8.544^{* * *}$ & 0.517 \\
\hline Spain & $0.004^{* * *}$ & $0.453^{* * *}$ & 0.005 & $0.618^{* * *}$ & $-3.844^{* * *}$ & 0.767 \\
\hline Sweden & $0.007^{\text {*** }}$ & $0.623^{* * *}$ & $0.038^{* * *}$ & $0.445^{* * *}$ & $-2.002^{* *}$ & 0.703 \\
\hline Switzerland & $0.004^{* * *}$ & $0.525^{* * *}$ & $0.030^{* * * *}$ & $0.591^{* * *}$ & $-2.614^{* *}$ & 0.792 \\
\hline Taiwan & $0.004^{* * * *}$ & $0.618^{* * *}$ & $-0.034^{* * *}$ & $0.512^{* * *}$ & $-7.192^{* * *}$ & 0.703 \\
\hline Thailand & $0.006^{* * *}$ & $0.456^{* * *}$ & -0.007 & $0.535^{* * *}$ & $-2.485^{* * *}$ & 0.781 \\
\hline United Kingdom & $0.005^{* * *}$ & $0.483^{* * *}$ & $0.037^{\text {***}}$ & $0.704^{* * *}$ & $-2.948^{*}$ & 0.807 \\
\hline United States & $0.001^{* * *}$ & $0.804^{* * *}$ & 0.002 & $0.190^{* * *}$ & $-1.387^{* * *}$ & 0.859 \\
\hline
\end{tabular}


Table 2. Individual effects of modulating variables on herding. We run 42 pool equations of cross-sectional absolute standard deviations (CSAD) on the past CSAD, market return, absolute market return, squared market return and squared market return interacting with individual modulating variables. Pool equation uses ordinary least squares regression with cross-section fixed effects, year dummies and log of GDP. The estimator is designed to accommodate heteroscedasticity (White cross section standard errors). The table reports the estimated coefficients for herding and herding interacting with individual modulating variables. ${ }^{* * *},{ }^{* *}$ and ${ }^{*}$ indicate statistical significance at $1 \%, 5 \%$ and $10 \%$ respectively.

Equation 1:

$\operatorname{CSAD}_{i, t}=\alpha+\gamma_{1} \operatorname{CSAD}_{i, t-1}+\gamma_{2} R m_{i, t}+\gamma_{3}\left|R m_{i, t}\right|+\gamma_{4}\left[R m_{i, t}\right]^{2}+\gamma_{5} D V_{i, t}^{s_{i, t}}\left[R m_{i, t}\right]^{2}+\gamma_{6} \log G D P_{i, t}+\varepsilon_{i, t}$

\begin{tabular}{|c|c|c|c|c|c|c|}
\hline \multicolumn{7}{|c|}{ Cultural Dimension } \\
\hline & pdi & idv & mas & uai & lto & ivr \\
\hline$\gamma_{4 \text { herd }}$ & $-3.643^{* * *}$ & $-5.193^{* * *}$ & $-4.326^{* * *}$ & $-4.649^{* * *}$ & $-4.471^{* * *}$ & $-5.284^{* * *}$ \\
\hline$\gamma_{5}$ herd*dv & $-1.609^{* * *}$ & $1.444^{* * *}$ & $-1.117^{* * *}$ & $-0.764^{* * *}$ & $-0.901^{* * *}$ & $2.073^{* * *}$ \\
\hline \multicolumn{7}{|c|}{ Governance Dimension } \\
\hline & va & ps & ge & $\mathrm{rq}$ & $\mathrm{rl}$ & $\mathrm{cc}$ \\
\hline$\gamma_{4 \text { herd }}$ & $-5.236^{* * *}$ & $-5.269^{* * *}$ & $-5.288^{* * *}$ & $-5.373^{* * *}$ & $-5.288^{* * *}$ & $-5.396^{* * *}$ \\
\hline$\gamma_{5 \text { herd*dv }}$ & $2.306^{* * *}$ & $2.726^{* * *}$ & $1.739^{* * *}$ & $2.099^{* * *}$ & $1.844^{* * *}$ & $2.685^{* * *}$ \\
\hline \multicolumn{7}{|c|}{ Education and training Dimension } \\
\hline & het & $\operatorname{arts}$ & ojt & est & ipp & qsri \\
\hline$\gamma_{4 \text { herd }}$ & $-5.197^{* * *}$ & $-5.274^{* * *}$ & $-5.257^{* * *}$ & $-5.447^{* * *}$ & $-5.433^{* * *}$ & $-5.350^{* * *}$ \\
\hline$\gamma_{5 \text { herd*dv }}$ & $0.653^{* * *}$ & $0.915^{* * *}$ & $0.881^{* * *}$ & $0.802^{* * *}$ & $1.827^{* * *}$ & $1.344^{* * *}$ \\
\hline
\end{tabular}

\begin{tabular}{|c|c|c|c|c|c|c|}
\hline \multicolumn{7}{|c|}{ Technology Dimension } \\
\hline & inn & srd & iui & tab & $\operatorname{trd}$ & fdi \\
\hline$\gamma_{4 \text { herd }}$ & $-5.040^{* * *}$ & $-5.116^{* * *}$ & $-5.211^{* * *}$ & $-5.303^{* * *}$ & $-5.346^{* * *}$ & $-5.750^{* * *}$ \\
\hline$\gamma_{5 \text { herd*dv }}$ & 0.010 & 0.165 & $0.373^{* *}$ & $0.514^{* * *}$ & $0.651^{* * *}$ & $2.264^{* * *}$ \\
\hline
\end{tabular}

\begin{tabular}{|c|c|c|c|c|c|c|}
\hline \multicolumn{7}{|c|}{ Business style and conditions Dimension } \\
\hline & wda & bir & $\mathrm{rpm}$ & ecb & sars & ethb \\
\hline$\gamma_{4 \text { herd }}$ & $-5.376^{* * *}$ & $-5.332^{* * *}$ & $-5.316^{* * *}$ & $-5.410^{* * *}$ & $-5.476^{* * *}$ & $-5.195^{* * *}$ \\
\hline$\gamma_{5 \text { herd }{ }^{*} \mathrm{dv}}$ & $1.121^{* * *}$ & $1.427^{* * *}$ & $1.953^{* * *}$ & $2.209^{* * *}$ & $2.355^{* * *}$ & $2.889^{* * *}$ \\
\hline
\end{tabular}

Financial development equity markets Dimension

\begin{tabular}{|c|c|c|c|c|c|c|}
\hline & pmsi & flem & eff & vca & tac & nlc \\
\hline$\gamma_{4 \text { herd }}$ & $-5.276^{* * *}$ & $-5.379^{* * *}$ & $-5.492^{* * *}$ & $-5.556^{* * *}$ & $-5.625^{* * *}$ & $-5.367^{* * *}$ \\
\hline$\gamma_{5 \text { herd }}{ }^{*} d v$ & $0.656^{* * *}$ & $0.696^{* * *}$ & $1.528^{* * *}$ & $1.637^{* * *}$ & $2.104^{* * *}$ & $0.473^{* * *}$ \\
\hline
\end{tabular}

\begin{tabular}{|c|c|c|c|c|c|c|}
\hline \multicolumn{7}{|c|}{ Financial development non-equity markets Dimension } \\
\hline & oipds & idi & lipv & nlipv & pfa & pcdmb \\
\hline$\gamma_{4 \text { herd }}$ & $-5.257^{* * *}$ & $-5.108^{* * *}$ & $-5.475^{* * *}$ & $5.496^{* * *}$ & $-5.379^{* * *}$ & $-5.088^{* * * *}$ \\
\hline$\gamma_{5}$ herd*dv & $1.908^{* * *}$ & $2.715^{\text {*** }}$ & $0.872^{* * *}$ & $1.120^{* * *}$ & $1.516^{* * *}$ & $0.326^{*}$ \\
\hline
\end{tabular}


Table 3. Combined effects of modulating dimensions on herding. We run 6 pool equations of cross-sectional absolute standard deviations (CSAD) on the past CSAD, market return, absolute market return and squared market return and squared market return interacting with modulating dimensions. Pool equation uses ordinary least squares regression with cross-section fixed effects, year dummies and log of GDP. The estimator is designed to accommodate heteroscedasticity (White cross section standard errors). The table reports the estimated coefficients of pool equations for herding, herding interacting with one single cultural variable (cv: pdi, idv, mas, uai, lto or ivr, alternatively) and herding together with orthogonalized modulating dimensions: gov (governance dimension), ed (education and training dimension), tech (technology dimension), bus (business style and conditions dimension), fd1 (financial development equity markets dimension) and fd2 (financial development non-equity markets dimension). ***, ${ }^{* *}$ and ${ }^{*}$ indicate statistical significance at $1 \%, 5 \%$ and $10 \%$ respectively.

Equation 2:

$$
\begin{aligned}
& \operatorname{CSAD}_{i, t}=\alpha+\gamma_{1} \operatorname{CSA} D_{i, t-1}+\gamma_{2} R_{m, t}+\gamma_{3}\left|R_{m, t}\right|+\gamma_{4}\left[R_{m, t}\right]^{2}+\gamma_{5} C V_{i, t}^{s_{i, t}}\left[R_{m, t}\right]^{2}+\gamma_{6} D F 1_{i, t}\left[R_{m, t}\right]^{2}+ \\
& \gamma_{7} \operatorname{TECH}_{i, t}\left[R_{m, t}\right]^{2}+\gamma_{8} D F 2_{i, t}\left[R_{m, t}\right]^{2}+\gamma_{9} B U S_{i, t}\left[R_{m, t}\right]^{2}+\gamma_{10} E D U_{i, t}\left[R_{m, t}\right]^{2}+\gamma_{11} G O V_{i, t}\left[R_{m, t}\right]^{2}+ \\
& \gamma_{12} \operatorname{LogGDP}_{i, t}+\varepsilon_{i, t}
\end{aligned}
$$

\begin{tabular}{|c|c|c|c|c|c|c|}
\hline$\gamma$ & Pool (pdi) & Pool (idv) & Pool (mas) & Pool (uai) & Pool (lto) & Pool (ivr) \\
\hline$\gamma_{4}$ & $-3.149^{* * *}$ & $-3.187^{* * *}$ & $-3.011^{* * *}$ & $-2.830^{* * * *}$ & $-3.138^{* * * *}$ & $-3.127^{* * *}$ \\
\hline$\gamma_{5 \text { herd }^{*} \mathrm{CV}}$ & 0.322 & $-0.920^{* * *}$ & $-1.245^{* * *}$ & $1.276^{* * *}$ & 0.073 & 0.227 \\
\hline$\gamma_{6 \text { herd }}{ }^{*} \mathrm{fd} 1$ & $0.791^{* * *}$ & $0.744^{* * *}$ & $0.717^{* * *}$ & $0.639^{* * *}$ & $0.806^{* * *}$ & $0.784^{* * *}$ \\
\hline$\gamma_{7 \text { herd*tech }}$ & $-0.713^{* * *}$ & $-0.690^{* * *}$ & $-0.893^{* * *}$ & $-0.856^{* * *}$ & $-0.723^{* * *}$ & $-0.756^{* * *}$ \\
\hline$\gamma_{8 \text { herd }{ }^{* f d} 2}$ & $0.891^{* * *}$ & $0.892^{* * * *}$ & $0.857^{* * *}$ & $0.940^{* * * *}$ & $0.864^{* * *}$ & $0.844^{* * *}$ \\
\hline$\gamma_{9 \text { herd*bus }}$ & $2.651^{* * * *}$ & $2.615^{* * *}$ & $2.459^{* * *}$ & $2.697^{* * * *}$ & $2.639^{* * *}$ & $2.679^{* * *}$ \\
\hline$\gamma_{10 \text { herd*edu }}$ & $0.9079^{* *}$ & $0.6237^{*}$ & 0.187 & $0.8448^{* *}$ & $0.989^{* *}$ & $0.944^{* *}$ \\
\hline$\gamma_{11 \text { herd*gov }}$ & $-0.928^{* * *}$ & $-0.890^{* * *}$ & $-0.805^{* * *}$ & $-1.020^{* * * *}$ & $-0.910^{* * *}$ & $-0.922^{* * *}$ \\
\hline
\end{tabular}




\section{References}

Barberis, N. and R. Thaler (2003) A Survey of behavioral finance'. In: G. Constantinides, R. Stulz, and M. Harris (eds.): Handbook of the Economics of Finance. North Holland.

Bikhchandani, S. and Sharma, S. (2001). Herd Behaviour in Financial Markets, IMF Staff Papers 47 (3): 279-310.

Boolaky P. K., Krishnamurti C., and Hoque, A., (2013) "Determinants of the Strength of Auditing and Reporting Standards: a Cross-Country Study" Australasian Accounting, Business and Finance Journal, 7(4), 17-36.

Chang, E. C., Cheng, J. W. and Khorana. A. (2000) An Examination of Herd Behavior in Equity Markets: An International Perspective. Journal of Banking and Finance, 24, 1651-1679.

Chang C-H. and Lin S-J. (2015) "The effects of national culture and behavioural pitfalls on investors'decision-making: Herding behaviour in international stock markets" International Review of Economics and Finance, 37, 380-392.

Chen T. (2013) "Do investors herd in global stock markets?" The Journal of Behavioral Finance, 14, 230-239.

Chiang T.C. and Zheng D. (2010) "An empirical analysis of herd behavior in global stock markets” Journal of Banking and Finance, 34, 1911-1921.

Davis-Friday, PY (2010) Discussion of 'Financial reporting quality in international settings: A comparative study of the U.S.A, Japan, Thailand, France and Germany', International Journal of Accounting, 45, 2, 35-38.

Francis, J. R., Khurana, I. K., and Pereira, R. (2003). The role of accounting and auditing in corporate governance and the development of financial markets around the world. Asia-Pacific Journal of Accounting \& Economics, 10(1), 1-30.

Fremount, A. S., Delbecg, A. L., and Cummings, L.L. (1970), "Organizational Decision Making ", McGraw Hill, New York.

Hofstede G. 2001. Culture's Consequences: Comparing Values, Behaviors. Institutions and Organizations across Nations. Sage Publication. Beverly Hills.

Hofstede. G., Hofstede G.J. and M. Minkov. 2010, Cultures and Organizations: Software of the Mind. Revised and Expanded 3rd Edition. New York: McGrawHill USA.

Hogarth, R. M. 2001. Educating Intuition. University of Chicago Press, Chicago.

Ince O.S. and R.B. Porter, (2006) "Individual equity return data from Thomson Datastream: Handle with care!" Journal of Financial Research, 29, 463-479. 
Kuran, T. and C. Sunstein (1999), 'Availability cascades and risk regulation'. Stanford Law Review 51, 683-768.

Lo, A. (1999) The three P's of total risk management. Financial Analysts Journal, 55, p.12-20.

Loewenstein, G. (2000) Emotions in economic theory and economic behavior. American Economic Review, 90, p.426-432.

Rahman, A, Yammeesri, J \& Perera, H. (2010) "Financial reporting quality in international settings: A comparative study of the U.S.A, Japan, Thailand, France and Germany" International Journal of Accounting, 45, 1, 1-34.

Shiller, R. (1999), "Human behavior and the efficiency of the financial system". In: J. Taylor and M. Woodford (eds.): Handbook of Macroeconomics. Amsterdam: Elsevier.

Shiller, R. and J. Pound (1989) "Survey evidence on the diffusion of interest and information among investors" Journal of Economic Behavior and Organization, $12,46-66$.

Sornette, D. and S. von der Becke (2011) "Crashes and High Frequency Trading. An evaluation of risks posed by high-speed algorithmic trading." The Future of Computer Trading in Financial Markets, Foresight Driver Review - DR 7. Government Office for Science. London.

Stasser, G., L. Taylor, and C. Hanna (1989) "Information sampling in structured and unstructured discussions of three- and six-person groups" Journal of Personality and Social Psychology, 57, 67-78.

Stasser, G. and W. Titus (1985) "Pooling of unshared information in group decision making: Biased information sampling during discussion” Journal of Personality and Social Psychology, 48, 1467-1478.

Velicer, W.F. (1976). Determining the number of components from the matrix of partial correlations, Psychometrika, 41, 321-327.

WDI: Governance Indicators

http://info.worldbank.org/governance/wgi/index.aspx\#home

Xue, Y., Gençay, R., and Wang, C. High frequency trading, noise herding and market quality. Working paper. Downloadable from http://citeseerx.ist.psu.edu/viewdoc/download?doi=10.1.1.696.7137\&rep=rep1\&ty pe $=$ pdf 